\title{
Ground-State Stem Cells: A Novel Approach for Adult Stem Cell Research
}

\author{
Wa Xian ${ }^{1,2 *}$, Marcin Duleba ${ }^{3}$, Yutao Qi ${ }^{3}$, Rajasekaran Mahalingam ${ }^{3}$, Matthew Vincent ${ }^{4}$, Frank McKeon ${ }^{3}$ \\ 'Institute of Molecular Medicine, McGovern Medical School of University of Texas Health Science Center, Houston, Texas 77030, USA \\ ${ }^{2}$ Department of Biochemistry and Molecular Biology, University of Texas McGovern Medical School, Houston, Texas 77030, USA \\ ${ }^{3}$ Department of Biology and Biochemistry, University of Houston, Houston, Texas 77204, USA \\ ${ }^{4}$ Tract Pharmaceuticals, Inc., Marlborough, Massachusetts 01752, USA
}

Article Info

\section{Article Notes}

Received: November 26, 2018

Accepted: December 31, 2018

\section{${ }^{*}$ Correspondence:}

Dr. Wa Xian, Institute of Molecular Medicine, McGovern Medical School of University of Texas Health Science Center, Houston, Texas 77030, USA; Telephone No: 1-860480-1188; Email: wa.xian@uth.tmc.edu.

(c) 2018 Xian W. This article is distributed under the terms of the Creative Commons Attribution 4.0 International License.

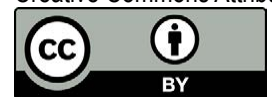

Keywords:

ground-state stem cells

autologous transplantation

regenerative medicine

drug screening

biobanking

\section{ABSTRACT}

A robust and reliable culture system of adult stem cells is essential for applying the cutting-edge technologies of drug screening, gene editing, and genomics to stem cell research necessary for breakthroughs in this field. In addition, personalized regenerative medicine based on autologous transplantation requires our ability to clone and expand the numbers of these stem cells in vitro. In comparison to the 3D "organoid" culture system that shows limited ability to propagate stem cells as the majority of cells are differentiated or transit amplifying cells, ground-state stem cell culture system is a novel technology that permits long-lived adult stem cells to maintain immaturity, self-renewal capacity, multi-potency and genomic stability despite long-term culturing in a 2D system. The robustness, reliability and easy-to-use features of this new technology bypass the deficiencies of 3D organoid culture systems and provided unlimited stem cell sources for research, therapeutic use, and drug discovery.

\section{The history of 3T3-J2 feeder system in adult stem cell culturing}

The 3T3-J2 feeder system was generated by Howard Green's lab in 1975 and since has been employed to culture various types of adult stem cells derived from stratified epithelium such as skin, cornea, thymus and lung ${ }^{1,2}$. Importantly, the J2 strain of 3T3 cells cleared regulatory hurdles for clinical more than thirty years ago without reports of adverse effects ${ }^{3-5}$. Despite the development of several feeder-free cell culture method $s^{6-8}$, methods based on the Rheinwald and Green culture protocol remain as the gold standard for clinical applications ${ }^{4}$ because of its high clonogenicity and regenerative capacity. However, regulatory considerations and the extensive time and effort required for preparation of murinederived feeder cells in this system limit the use of these stem cells for downstream applications including regenerative medicine. Thus, moving towards feeder-free culture system for adult stem cells would represent an essential and important improvement.

Despite the remarkable track record of the Green method for cloning stem cells of stratified epithelia, it proved ineffective for cloning stem cells of columnar epithelia such as the liver, gastrointestinal tract, and kidney. Therefore, we developed a new technology using a combination of 3T3-J2 feeder cells and a specialized medium to clone ground-state stem cells from human fetal and adult columnar epithelium $^{9-11}$. Importantly, this system enables the maintenance of stem cells with extremely high clonogenicity in culture so sufficient numbers required for downstream applications can be reached in 
a short time. In addition, the adult stem cells cultured in these feeder systems maintain the ability of regiospecific differentiation ${ }^{1,9,12,13}$.

\section{Comparison between organoids and ground-state stem cell cloning technology}

Since the 1980s, the researchers began to use 3D culture systems in which mammalian cells are grown in collagen and laminin-rich matrices as organoids ${ }^{14-18}$. Organoid technology has allowed some fundamental advances in stem cell research, however, it doesn't support culturing the intestinal stem cells or any other adult stem cells in their highly clonogenic and immature state. Importantly, the transit amplifying cells that have lost stem cell capacity can also generate organoids because they still have limited proliferative potential, thus organoids are not assays for stem cells ${ }^{19}$.

The ground-state stem cell cloning technology solved the problem of cloning and culturing of highly-clonogenic stem cells derived from both fetal and adult human gastrointestinal tract epithelium. This system includes 3T3-J2 feeder cells and a specialized media using a cocktail of factors impacting Wnt, Notch, and TGF-beta signaling pathways among others ${ }^{9,11}$. Significantly, using this system, normal stem cells of stomach, intestine as well as stem cells of precancerous lesions such as Barrett's esophagus can be cloned from $1 \mathrm{~mm}$ endoscopic biopsies ${ }^{10,11}$. Furthermore, we anticipate that this technology can also support cloning and culturing of stem cells of other columnar epithelium such as pancreas and liver. Therefore, stem cells of columnar epithelia can be routinely captured and cultured in the same ground state that Howard Green had shown for the stem cells of epidermis.

In comparison with widely used organoid systems, we found the following properties of these ground-state stem cells make this technology particularly advantageous: 1. We can generate approximately 100 stem cell clones from a typical $1 \mathrm{~mm}$ endoscopic biopsy, which preserves the potential clonal diversity of intestinal crypts; 2 . We can expand each of these clones as pedigrees and reach 1 billion progeny cells in approximately sixty days. This unique feature allows us to obtain sufficient cell number rapidly for time-sensitive applications such as autologous transplantation. 3. These stem cells maintain genomic integrity despite long-term culturing which reduces safety concerns for using them for regenerative medicine. 4 . The cultured ground-state stem cells uniformly express stem cell markers and have high clonogenicity rate of $60-90 \%$; 5 . The ground state stem cell clones retain permanent epigenetic memory of regiospecificity. 6 . The ground state stem cells maintain long-term multipotent differentiation ability so the stem cells of a single cell derived pedigree can be differentiated to yield 3- $D$ intestinal epithelia with regionally appropriate cell types despite extensive cultivation in vitro. 7 . We can clone stem cells from all donors despite age, sex, and disease status and maintain comparable clonogenicity of cultured stem cells across patients.

\section{The future applications of ground-state stem cells}

Our ability of producing unlimited number of adult stem cells in culture provides the opportunities of rapidly advancing their utility in disease modeling, drug discovery, biobanking, and personalized regenerative medicine,

Since stem cells can be derived from both normal and diseased tissue, expanded in culture and induced to differentiate into artificial 3D tissue that recapitulate their in vivo counterparts, they are ideal model system for investigating the cellular and molecular mechanisms underlying these diseases. If the long-term regenerative growth of diseased stem cells is distinct from those that support the nearby normal epithelium, these differences should render diseased stem cells selectively targetable ${ }^{20}$. The rapid expansion of ground-state stem cells provides sufficient number of cells enabling moderate and even high-throughput testing of small molecule, biologics, or even immunologic approaches to the selective eradication of the diseased stem cells in a manner that would spare those of normal epithelia. It is conceivable that if such studies are validated both in vitro and in vivo, they could yield small molecules and biologics that could be used to improve patient care and outcome.

For personalized regenerative medicine, Howard Green and colleagues demonstrated the feasibility of cultured wild-type or genetically-modified adult stem cells being transplanted to patients for the purpose of regenerative medicine. This is a life-saving procedure for patients with large area of burns or with severe genetic disease ${ }^{21-23}$. We anticipate that this newfound ability to derive ground-state stem cells from columnar epithelium provides excellent sources for autologous transplantation to treat a wide range of disorders which current treatments are not able to help. For example, the intestinal epithelial functions in patients with severe forms of short bowel syndrome (SBS) ${ }^{24}$, or those with congenital disorders ${ }^{25}$ or inflammatory bowel disease (IBD) ${ }^{26,27}$ may be restored following autologous transplantation of cultured wild-type or genetically-edited ground-state intestinal stem cells. Furthermore, more and more stem cell researchers may realize the potential of biobanking various types of adult stem cells from individuals of diverse HLA haplotypes and make attempts to use them for stem-cell-based personalized regenerative medicine.

Taken together, with the recognition and utilization of ground-state stem cell cloning technology in research and medicine, we hope that in the foreseeable future 
new adult-stem-cell-based therapeutic options can be developed to help patients with incurable chronic and terminal illnesses.

\section{Acknowledgements}

This work was supported by grants from the Cancer Prevention Research Institute of Texas (CPRIT; to WX and to FM), the National Institutes of Health (to WX, and FM), the US Dept. of Defense (to WX), the University of Texas Presidential Award (to WX) and the American Gastroenterology Association Research and Development Pilot Award in Technology (to WX). We thank all the members in the Xian-McKeon laboratory for helpful discussions and support. We thank H. Green for advice and support.

\section{Author contributions to manuscript}

Conceptualization, W.X. and F.M.; Writing-Original Draft Preparation, W.X., M.V., M.D., and F.M; Writing-Review \& Editing, W.X., YQ R.M., M.D., and F.M; Supervision, W.X. and F.M.; Funding Acquisition, W.X. and F.M.

\section{Conflict of interest statement}

W.X., F.M., M.D. and M.V. have filed a patent related to the technology used in the present work.

\section{References}

1. Rheinwald JG, Green H. Serial cultivation of strains of human epidermal keratinocytes: the formation of keratinizing colonies from single cells. Cell. 1975; 6(3): 331-343. http://www.ncbi.nlm.nih.gov/ pubmed/1052771. Accessed November 11, 2018.

2. Senoo M, Pinto F, Crum CP, et al. p63 Is Essential for the Proliferative Potential of Stem Cells in Stratified Epithelia. Cell. 2007; 129(3): 523536. doi:10.1016/j.cell.2007.02.045

3. Llames S, García-Pérez E, Meana Á, et al. Feeder Layer Cell Actions and Applications. Tissue Eng Part B Rev. 2015; 21(4): 345-353. doi:10.1089/ten.TEB.2014.0547

4. De Luca M, Pellegrini G, Green H. Regeneration of squamous epithelia from stem cells of cultured grafts. Regen Med. 2006; 1(1): 45-57. doi:10.2217/17460751.1.1.45

5. Green H. The birth of therapy with cultured cells. BioEssays. 2008; 30(9): 897-903. doi:10.1002/bies.20797

6. Boyce ST, Ham RG. Calcium-regulated differentiation of normal human epidermal keratinocytes in chemically defined clonal culture and serum-free serial culture. J Invest Dermatol. 1983; 81(1 Suppl): 33s-40s. http://www.ncbi.nlm.nih.gov/pubmed/6345690. Accessed November 11, 2018.

7. De Corte P, Verween G, Verbeken G, et al. Feeder layer- and animal product-free culture of neonatal foreskin keratinocytes: improved performance, usability, quality and safety. Cell Tissue Bank. 2012; 13(1): 175-189. doi:10.1007/s10561-011-9247-3

8. Lenihan $C$, Rogers $C$, Metcalfe AD, et al. The effect of isolation and culture methods on epithelial stem cell populations and their progeny-toward an improved cell expansion protocol for clinical application. Cytotherapy. 2014; 16(12): 1750-1759. doi:10.1016/j. jcyt.2014.06.005

9. Wang X, Yamamoto Y, Wilson LH, et al. Cloning and variation of ground state intestinal stem cells. Nature. 2015; 522(7555): 173-178. doi:10.1038/nature14484

10. Yamamoto Y, Wang X, Bertrand D, et al. Mutational spectrum of Barrett's stem cells suggests paths to initiation of a precancerous lesion. Nat Commun. 2016; 7: 10380. doi:10.1038/ncomms10380

11. Duleba M, Qi Y, Mahalingam R, et al. An Efficient Method for Cloning Gastrointestinal Stem Cells from Patients via Endoscopic Biopsies. Gastroenterology. October 2018. doi:10.1053/j.gastro.2018.08.062

12. Kumar PA, Hu Y, Yamamoto Y, et al. Distal Airway Stem Cells Yield Alveoli In Vitro and during Lung Regeneration following H1N1 Influenza Infection. Cell. 2011; 147(3): 525-538. doi:10.1016/j. cell.2011.10.001

13. Zuo W, Zhang T, Wu DZ, et al. p63(+)Krt5(+) distal airway stem cells are essential for lung regeneration. Nature. 2015; 517(7536): 616620. doi:10.1038/nature13903

14. Lee G, Hynes R, Kirschner M. Temporal and spatial regulation of fibronectin in early Xenopus development. Cell. 1984; 36(3): 729740. http://www.ncbi.nlm.nih.gov/pubmed/6697394. Accessed November 11, 2018.

15. Bissell DM, Arenson DM, Maher JJ, et al. Support of cultured hepatocytes by a laminin-rich gel. Evidence for a functionally significant subendothelial matrix in normal rat liver. J Clin Invest. 1987; 79(3): 801-812. doi:10.1172/JCI112887

16. Barcellos-Hoff MH, Aggeler J, Ram TG, et al. Functional differentiation and alveolar morphogenesis of primary mammary cultures on reconstituted basement membrane. Development. 1989; 105(2): 223-235. http://www.ncbi.nlm.nih.gov/pubmed/2806122. Accessed November 11, 2018.

17. Petersen OW, Rønnov-Jessen L, Howlett AR, et al. Interaction with basement membrane serves to rapidly distinguish growth and differentiation pattern of normal and malignant human breast epithelial cells. Proc Natl Acad Sci U S A. 1992; 89(19): 9064-9068. doi:10.1073/PNAS.89.19.9064

18. Sato T, Vries RG, Snippert HJ, et al. Single Lgr5 stem cells build cryptvillus structures in vitro without a mesenchymal niche. Nature. 2009; 459(7244): 262-265. doi:10.1038/nature07935

19. Simian M, Bissell MJ. Organoids: A historical perspective of thinking in three dimensions. J Cell Biol. 2017; 216(1): 31-40. doi:10.1083/ jcb.201610056

20. Xian W, McKeon F. Barrett's Stem Cells as a Unique and Targetable Entity. Cell Mol Gastroenterol Hepatol. 2017; 4(1): 161 164. doi:10.1016/j.jcmgh.2017.04.005

21. Green H, Kehinde O, Thomas J. Growth of cultured human epidermal cells into multiple epithelia suitable for grafting. Proc Natl Acad Sci U S A. 1979; 76(11): 5665-5668. http://www.ncbi.nlm.nih.gov/ pubmed/293669. Accessed November 11, 2018.

22. O'Connor N, Mulliken J, Banks-Schlegel S, et al. GRAFTING OF BURNS WITH CULTURED EPITHELIUM PREPARED FROM AUTOLOGOUS EPIDERMAL CELLS. Lancet. 1981; 317(8211): 75-78. doi:10.1016/ S0140-6736(81)90006-4

23. Hirsch T, Rothoeft T, Teig N, et al. Regeneration of the entire human epidermis using transgenic stem cells. Nature. 2017; 551(7680): 327 332. doi:10.1038/nature24487

24. Buchman AL, Scolapio J, Fryer J. AGA technical review on short bowel syndrome and intestinal transplantation. Gastroenterology. 2003; 124(4): 1111-1134. doi:10.1053/gast.2003.50139a

25. Hong SN, Dunn JCY, Stelzner M, et al. Concise Review: The Potential Use of Intestinal Stem Cells to Treat Patients with Intestinal Failure. Stem Cells Transl Med. 2017; 6(2): 666-676. doi:10.5966/sctm.20160153 
26. Salim SY, Söderholm JD. Importance of disrupted intestinal barrier in inflammatory bowel diseases. Inflamm Bowel Dis. 2011; 17(1): 362 381. doi:10.1002/ibd.21403
27. Martini E, Krug SM, Siegmund B, et al. Mend Your Fences: The Epithelial Barrier and its Relationship With Mucosal Immunity in Inflammatory Bowel Disease. Cell Mol Gastroenterol Hepatol. 2017; 4(1): 33-46. doi:10.1016/j.jcmgh.2017.03.007 